\title{
Impact of urban expansion on potential flooding, storage and water harvesting in the city of Sharjah, United Arab Emirates
}

\author{
Abdallah Shanableh ${ }^{l,}{ }^{*}$, Rami Al-Ruzouq ${ }^{l}$, Mohsin Siddique $^{l}$, Tarek Merabtene ${ }^{l}$, Abdullah \\ Yilmaz ${ }^{1}$, and Monzur Imteaz ${ }^{2}$ \\ ${ }^{1}$ Department of Civil and Environmental Engineering, University of Sharjah, United Arab Emirates \\ ${ }^{2}$ Swinburne University of Technology, Australia
}

\begin{abstract}
The work presented in this article is an extension of an earlier study [1] in which runoff in the city of Sharjah, United Arab Emirates (UAE), was assessed for the period 1967-2010. In this study, the impacts of urban expansion on potential flooding, storage and water harvesting were assessed for the period 1976-2016 using rainfall data recorded during the same period. Sharjah is a generally a flat coastal city that is located in a dry hot region average rainfall of approximately $100 \mathrm{~mm} / \mathrm{y}$. Remote sensing and GIS techniques were used to assess the expansion of built areas in the city using multi-temporal Landsat satellite images. The built areas in the city increased during the study period by approximately four folds while the population increased by more than 10 folds. The study results demonstrate the historical increase in runoff potential, flooding potential and runoff coefficient and decline in water storage potential. The results are consistent with the observed incidence of significant local flooding episodes in urban areas during rainfall events. Furthermore, an assessment of potential urban water harvesting based on expansion of built areas in the city is provided and appropriate urban storm water management practices for the city are recommended.
\end{abstract}

\section{Introduction}

Sharjah city is the capital and largest city in the Emirates of Sharjah, one of seven emirates that make the United Arab Emirates UAE). Sharjah is a coastal city located in a dry hot region, with mean daily high temperatures of $24-42^{\circ} \mathrm{C}$ and daily mean temperatures of 18 $34^{\circ} \mathrm{C}$. The rainy months are typically November to April, with average rainfall of approximately $100 \mathrm{~mm} / \mathrm{y}$. Figure 1 shows the UAE map and the Landsat image of Sharjah city, with the study area identified.

The UAE has experienced rapid growth and development during the study period, 19762016. Urbanization leads to expansion of built areas and land cover changes, which have significant impacts on runoff quantity and quality. Urbanization can also leads to changes in

\footnotetext{
* Corresponding author: shanableh@sharjah.ac.ae
} 
evapotranspiration, interception and sediments suspension and transport. It also impacts infiltration and stream flow and changes the time of concentration and runoff speed.

Multi-temporal remote sensing has applications in many fields and is especially useful for detecting and analysing historical land use changes. Remote sensing data integrated into an appropriate geographic information system (GIS) allow analysis and visual display of the data. Integration of remote sensing and GIS allows assessment of historical land use changes, identification of urban features, building a database suitable for analysing runoff change, and estimating hydrological model data in a practical and cost-effective manner [2-8].

Traditional change detection studies are based on visual/manual comparison of temporal images. Recently, however, automatic, reliable, and fast land feature change detection techniques have been developed. Such techniques that rely on identifying feature differences at different times [9] are essential to reduce the high cost associated with spatial data updating activities. In this study, both traditional and automatic feature detection were used to assess land use changes during the study period, 1976-2016.

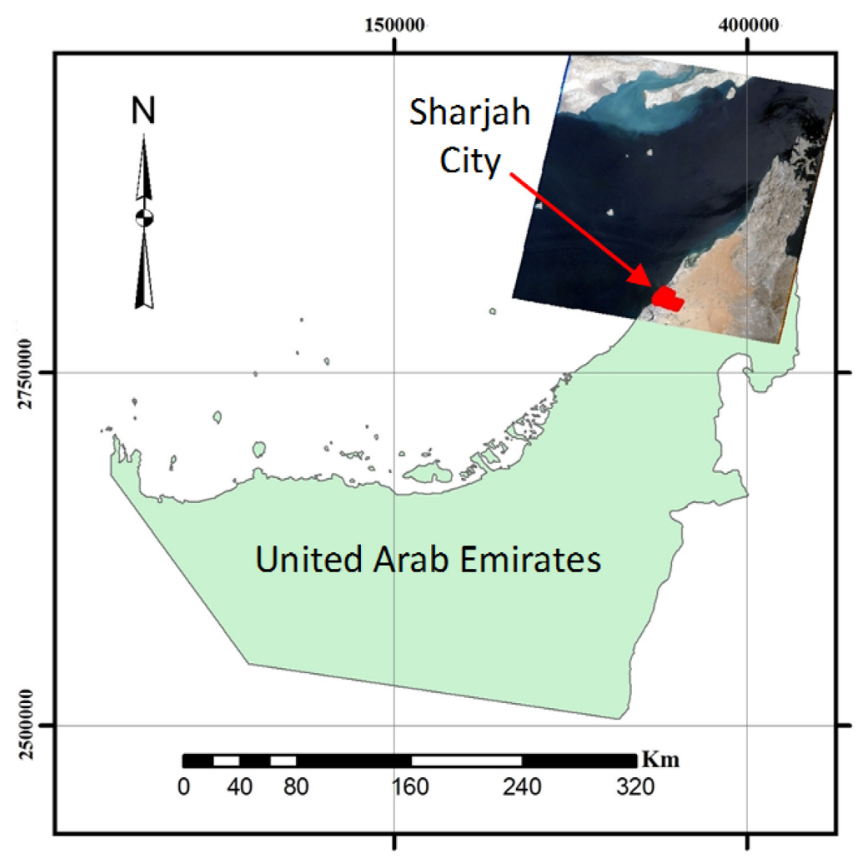

Fig. 1. Location of City of Sharjah in the UAE.

The main objective of this study was to assess the historical impact of land use change on potential flooding, storage and water harvesting in Sharjah during the period 1976-2016 using rainfall data recorded during the same period. The study was based on detecting land use changes using multi-temporal Landsat satellite images and GIS techniques. Furthermore, an assessment of potential urban water harvesting based on expansion of built areas in the city is provided and appropriate urban storm water management practices for the city are recommended. The study documents the historical expansion of the city and presents valuable information to help guide urban storm water management and future expansion of the city. 


\section{Methodology}

\subsection{Landcover change detection}

Two methods were used to assess land use changes in Sharjah during the study period 19762016: (1) multi-temporal image analysis, and (2) manual digitization of land features. In the first method, land cover changes were assessed through detecting and registering linear features in multi-temporal Landsat satellite images obtained for the study period. Image analysis involved linear feature extraction, image registration and pixel-pixel subtraction using Landsat images with different spatial and temporal resolutions. Straight-line segments have high semantics and can be reliably extracted from the images. These linear features represent the streets and buildings in urban areas and are used as the base for change detection. Select interest and well distributed points were manually digitized for registration to drive the transformation parameters needed for the image registration.

The second method was based on classifying the different land use features and digitizing them manually based on visual inspection and knowledge of the area. Older images had lower resolution but fortunately many of the old features remained standing and appeared in recent images. As the digitization process is tedious, saturated urban blocks were digitized as units and the digitized areas were distributed on the different land uses by ratio. Examples of digitized areas using the two methods are shown in Figure 2.
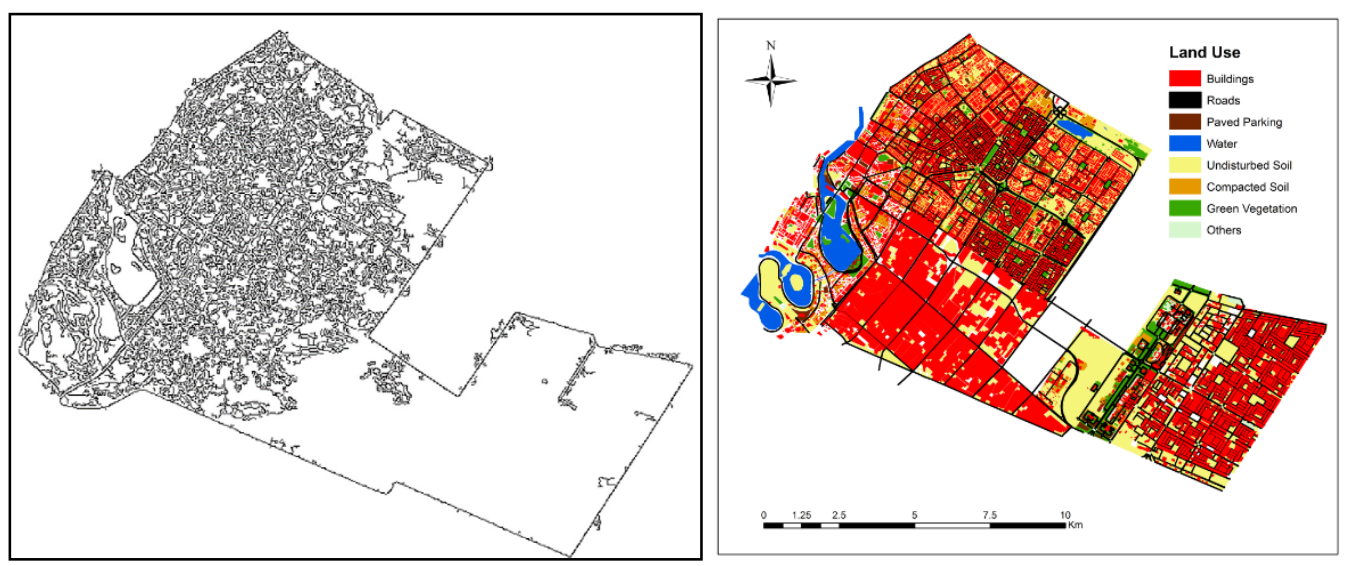

Fig. 2. Examples showing estimation of land use using: edge detection of built features; and direct digitization of features.

\subsection{Runofff analysis}

The methodology used to estimate the distributed runoff in the city was based on the procedure outlined by [10] and [11]. The US Soil Conservation Service (SCS) model was used to estimate runoff changes in Sharjah. The model is based on assigning curve numbers (CN) representing the runoff characteristics of the different land uses. The SCS model equations are presented below:

$$
Q=\frac{[P-0.2 S]^{2}}{P+0.8 S}
$$




$$
S=25.4\left(\frac{1000}{C N}-10\right)
$$

where, $\mathrm{S}=$ potential maximum storage $(\mathrm{mm}), \mathrm{Q}=$ runoff depth $(\mathrm{mm}), \mathrm{P}=$ cumulative precipitation ( $\mathrm{mm}) ; \mathrm{CN}=$ curve number.

Solving Equation 1 requires two parameters; P and CN. The SCS Equation 1 suggests that the minimum rain to generate runoff is $\mathrm{P}=0.2 \mathrm{~S}$. For a given antecedent moisture condition, the curve number is determined by the type of urban land cover and extend of urbanization. For purposes of estimating appropriate $\mathrm{CN}$ values, the manually digitized features were divided into five land use areas: high population density; residential/commercial mixed-use; residential; industrial; and public. Each of the five areas was further subdivided into five sub-areas; buildings, roads, paved parking/space, undisturbed soil, compacted soil, vegetation, and others. The undeveloped open area included the undisturbed soil, the compacted soil and vegetation, and the built areas included the remaining land features. Curve numbers (Table 1) were assigned to the different land uses based on standard SCS tables [12].

Table 1. Curve numbers assigned to the different land uses.

\begin{tabular}{|c|c|c|c|c|c|c|}
\hline $\begin{array}{c}\text { Built } \\
\text { Area }\end{array}$ & $\begin{array}{c}\text { Compact } \\
\text { Soil }\end{array}$ & $\begin{array}{c}\text { Undisturbed } \\
\text { Soil }\end{array}$ & Vegetation & Roads & $\begin{array}{c}\text { Paved } \\
\text { Parking }\end{array}$ & Others \\
\hline 90 & 80 & 75 & 90 & 90 & 87 & 87 \\
\hline
\end{tabular}

Composite $\mathrm{CN}$ values $(\overline{\mathrm{CN}})$ were weighed according to their corresponding areas $\left(A_{i}\right.$ ), as in Equation 3:

$$
\overline{\mathrm{CN}}=\frac{\sum C N_{i} * A_{i}}{\sum A_{i}}
$$

The runoff coefficient, C, can be estimated from runoff, Q, per precipitation event, $\mathrm{P}$, as in Equation 4:

$$
C=\frac{Q}{P}
$$

Potential water harvesting was quantified based on recovery of $80 \%$ of precipitation from $80 \%$ of built areas (i.e., $80 \%$ of built areas was assumed to be rooftops of buildings). The potential water harvest per capita was estimated using estimated population of the city, as in Equation 5.

$$
\text { Harv. }=\frac{0.64 * P^{*} A_{\text {Buildings }}}{\text { Population } * \text { No. of Days }}
$$




\subsection{Rainfall}

Based on data obtained from Sharjah Airport Authority's weather station, Figures 3 and 4 show the annual and average monthly rainfall in Sharjah during 1977-2014. The statistical average, maximum, and minimum values of rainfall in Sharjah during the same period are $108.8 \mathrm{~mm}, 318.9 \mathrm{~mm}$ and $8.6 \mathrm{~mm}$, respectively.

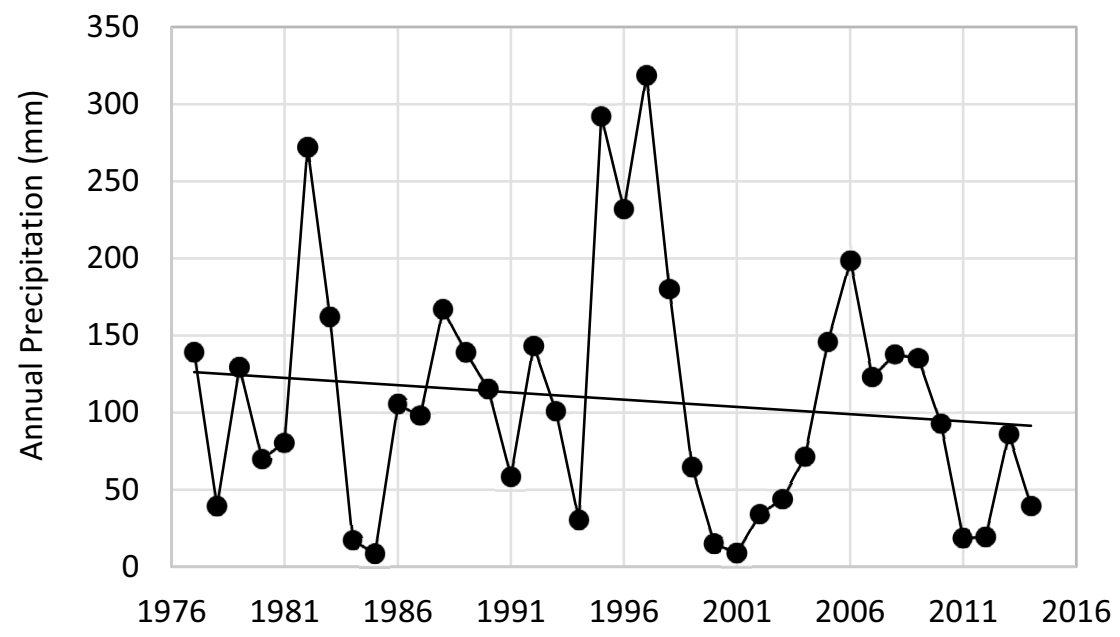

Fig. 3. Annual rainfall recorded at Sharjah International Airport during 1977-2014 and average rainfall during the same period.

The rainy season in Sharjah, as shown in Figure 4, may be considered to span from November to April (6 Months). An analysis of month rainfall shows that $93 \%$ of total annual rainfall is received during the Rainy season.

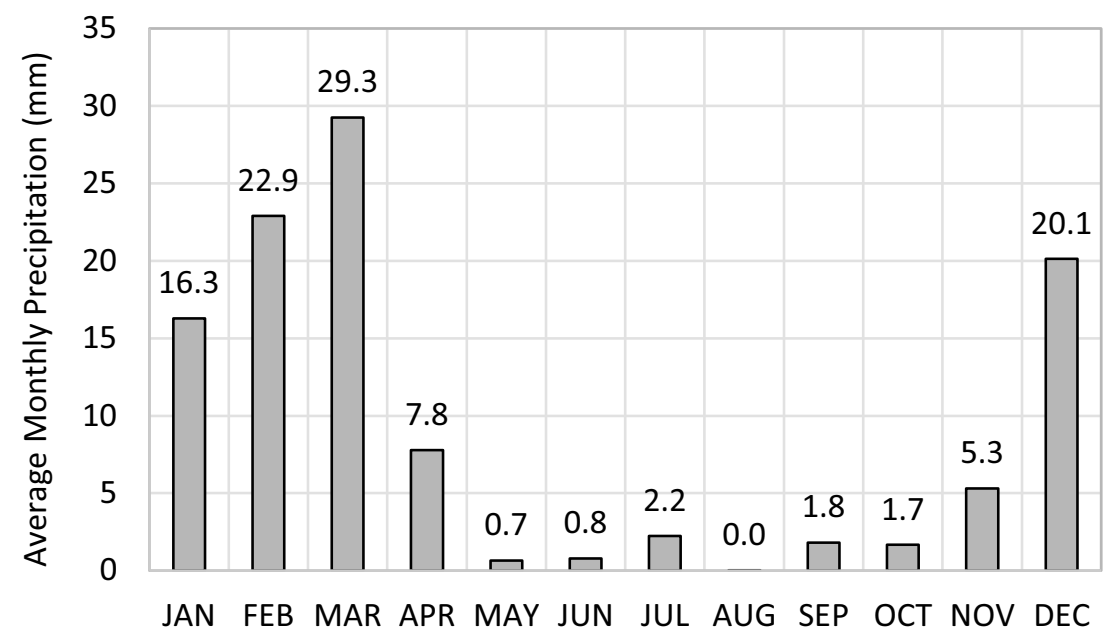

Fig. 4. Average monthly rainfall recorded at Sharjah International Airport during 1977-2014.

Sherif et al. (2013) produced intensity-duration-frequency (IDF) curves for the United Arab Emirates. A range of IDF and rainfall values based on Sherif's work are presented in 
Table 2. For all practical reasons, the data in Table 2 show that the range of precipitation per event is less than $100 \mathrm{~mm}$. Therefore, the runoff characteristics in the city were evaluated for precipitation between $17 \mathrm{~mm}$ to $120 \mathrm{~mm}$, with $17 \mathrm{~mm}$ being the minimum precipitation required to generate runoff based on the choice of $\mathrm{CNs}$ for the open areas.

Table 2. Range of rainfall intensity-duration-frequency and rainfall for the UAE desert foreland [13].

\begin{tabular}{|c|c|c|c|c|}
\hline & \multicolumn{2}{|c|}{$\mathbf{1 0 0 0}$ Years Return Period } & \multicolumn{2}{c|}{ 2 Years Return Period } \\
\hline Duration (min) & Intensity (mm/hr) & Rainfall (mm) & Intensity (mm/hr) & Rainfall (mm) \\
\hline 5 & 250 & 21 & 50 & 4 \\
\hline 25 & 130 & 54 & 25 & 10 \\
\hline 50 & 75 & 63 & 18 & 15 \\
\hline 100 & 50 & 83 & 10 & 17 \\
\hline 150 & 35 & 88 & 7 & 18 \\
\hline 200 & 30 & 100 & 6 & 20 \\
\hline
\end{tabular}

\section{Results and discussion}

\subsection{Growth and expansion of Sharjah city}

The data in Figure 5 show that the built areas within the various landuses expanded during the period 1976 to 2016. Overall, the built areas expanded by approximately four times; from approximately $25 \mathrm{~km}^{2}$ to about $120 \mathrm{~km}^{2}$. At the same time, the undeveloped open areas declined from approximately $100 \mathrm{~km}^{2}$ in 1976 to about $10 \mathrm{~km}^{2}$ in 2016 .

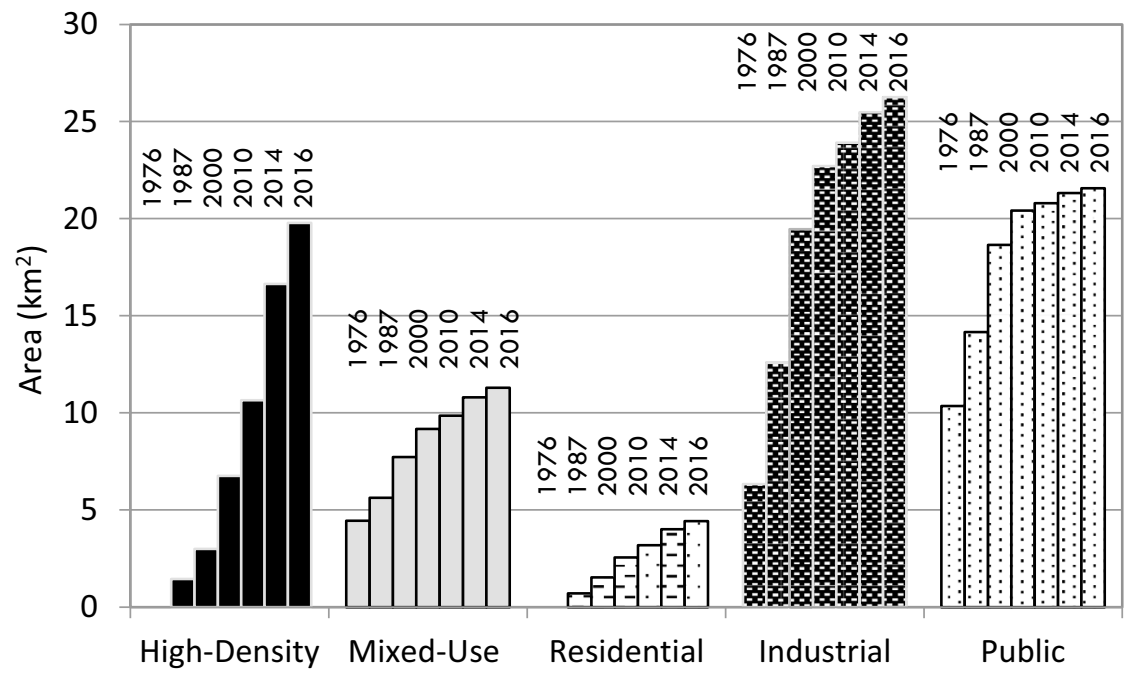

Fig. 5. Expansion of the various landuses in the city of Sharjah during 1976-2016.

Comparison of built and open areas estimated from Landsat images using the direct digitization and edge-detection techniques are shown in Figure 6. Compared to the 
digitization technique, the edge-detection technique significantly over-estimated built areas and underestimated open areas. It should be noted that the open and built areas estimated using the digitization technique were used in this study. The estimated population of Sharjah city grew from approximately 80,000 people in 1976 to approximately 1 million in 2016, which represents more than 10-fold increase. The expansion of built areas and dramatic population growth reflect the rapid economic growth of Sharjah and the UAE.
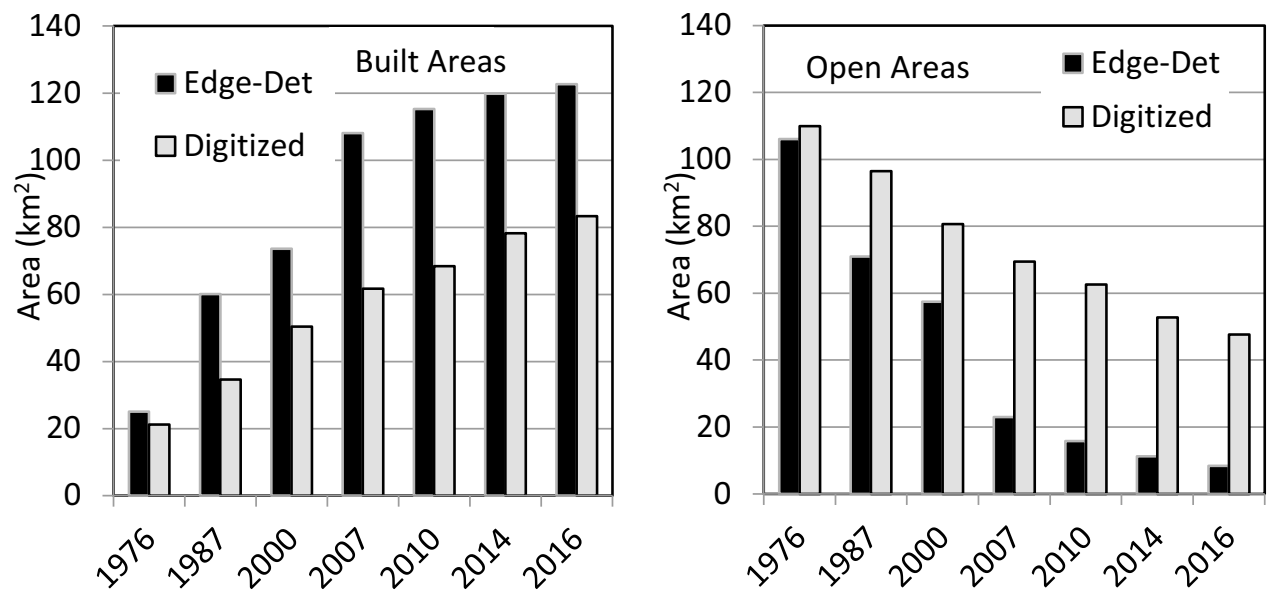

Fig. 6. Comparison of built and open areas estimated from satellite images using either of two methods: (1) direct digitization of features; and (2) edge-detection.

\subsection{Flooding, storage and water harvesting potentials}

Due to rain scarcity, Sharjah city authorities did not invest in a comprehensive drainage system. However, as the city grew, localized flooding events, although infrequent, affected many neighbourhoods and disrupted transportation and business activity. Therefore, the community increasingly demanded and concerned government authorities realized the need for a proper drainage system.

The historical expansion of built areas (Figures 5 and 6) resulted in at least three impacts that increase potential flooding, which are: (1) increase in imperviousness of land cover; (2) reduction in quantity of precipitation required to generate runoff; and (3) reduction in the maximum potential storage. As a result, local flooding severity and extent increased significantly.

The changes in flooding characteristics during the period 1976 to 2016 are shown graphically in Figure 7 . The minimum precipitation required to generate runoff $\left(\mathrm{P}_{\mathrm{Min}}\right)$ in the various zones of the city is also shown in Figure 7. The data show that $\mathrm{P}_{\text {Min }}$ declined in the various zones with time as the built areas, and consequently impervious areas, expanded. The minimum precipitation declined from about $13-17 \mathrm{~mm}$ in 1976 to about 7-11 $\mathrm{mm}$ in 2016 . For open areas alone, $\mathrm{P}_{\mathrm{Min}}$ was about $17 \mathrm{~mm}$, and theoretically no excess rain is expected from such areas below $\mathrm{P}_{\mathrm{Min}}=17 \mathrm{~mm}$, as shown in Figure 7. However, at $\mathrm{P}=17 \mathrm{~mm}$, excess rain from built areas increased with time. At $\mathrm{P}=34.4 \mathrm{~mm}$, which is the 24-hours maximum daily rainfall [13], excess rain from open areas declined over the years as the built areas expanded, Figure 7. 

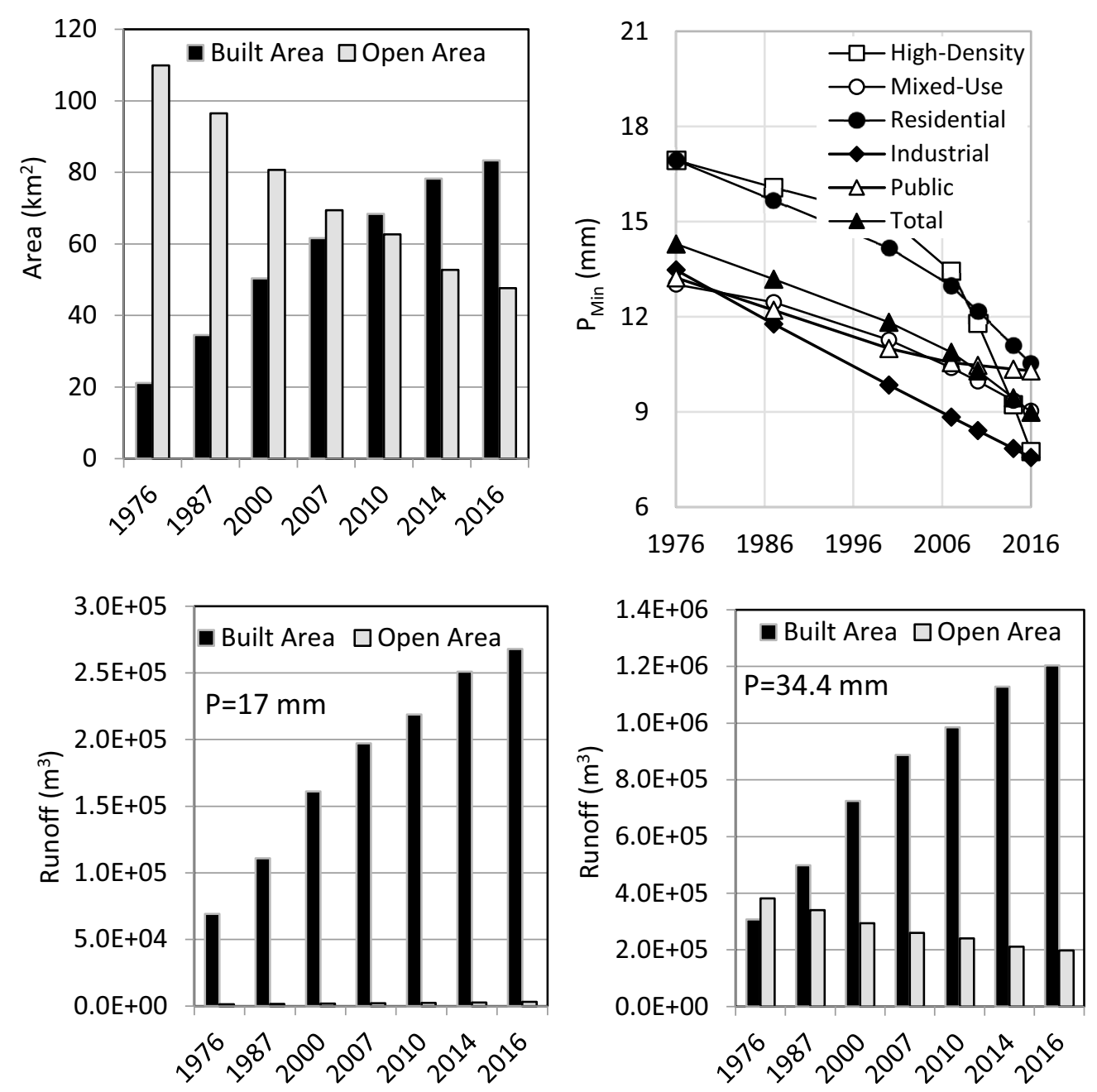

Fig. 7. Expansion in built areas in Sharjah city and impacts on runoff: (a) historical change in open/built areas; (b) historical change in minimum rain required to generate runoff (PMin); (c) excess rain at $\mathrm{P}=$ $17 \mathrm{~mm}$; and (d) excess rain at 24-hours maximum.

The historical increase in runoff $(\mathrm{Q})$ in the Sharjah city is shown in Figure 8. With the fraction of built areas increasing from $16 \%$ in 1976 to approximately $65 \%$ in 2016 , the runoff coefficient increased from approximately 0.1 in 1976 to 0.6 in 2016 . The results in Figure 8 show that change in runoff coefficient with urbanization declines as rainfall increases. According to the SCS model, the increase in runoff with urbanization results from the decrease in the maximum potential storage, $\mathrm{S}$, as shown in Figure 9. The potential storage is determined by the curve number, $\mathrm{CN}$, as in Equation 2, and changing the land cover and expanding urban areas increases the $\mathrm{CN}$ and therefore decreases S. The data in Figure 9 show the historical maximum storage declining in the various zones of the city between 1976 and 2016, with the overall city storage declining from about $71 \mathrm{~mm}$ in 2016 to about $45 \mathrm{~mm}$ in 2016. 

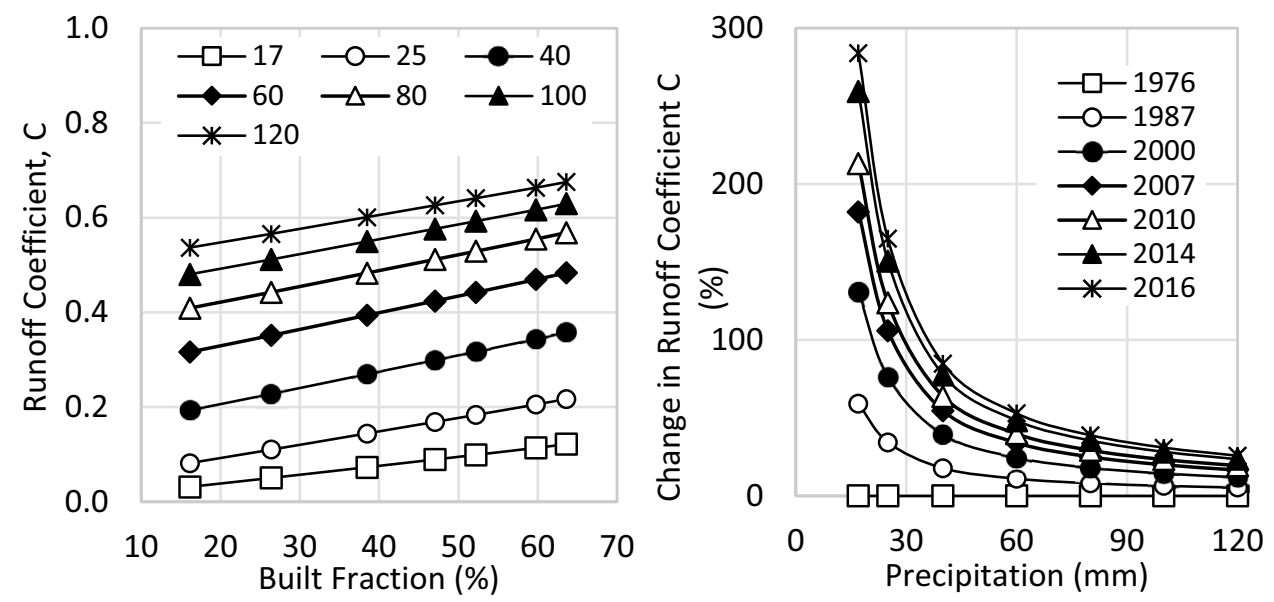

Fig. 8. Increase in runoff and runoff coefficient as a result of expansion in built areas in Sharjah city.
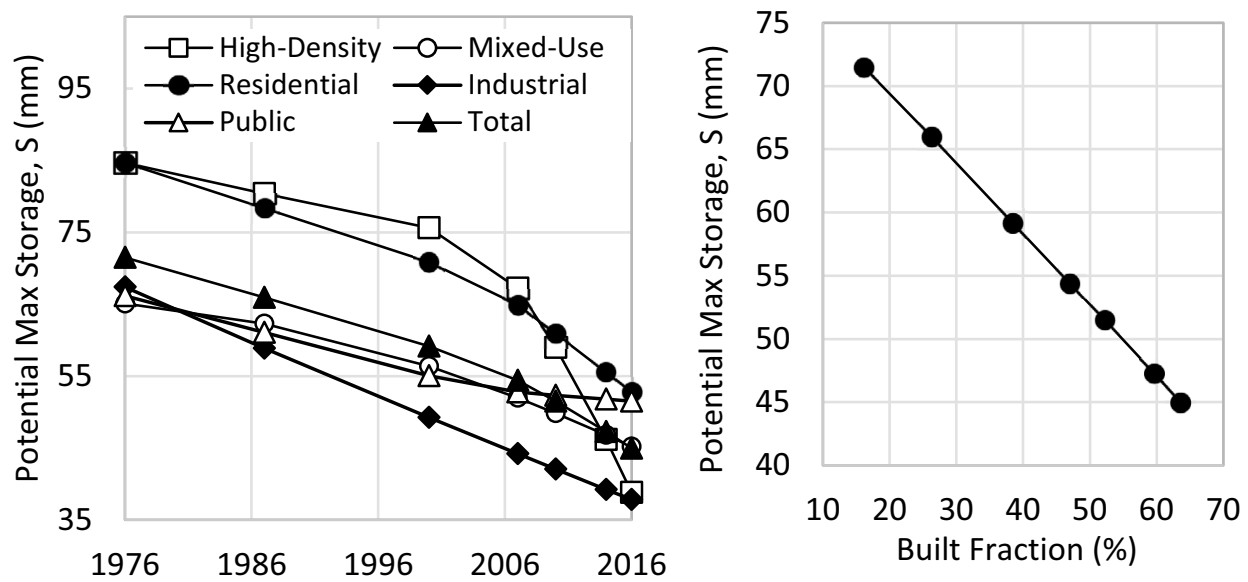

Fig. 9. Decline in potential maximum storage as a result of expansion in built areas in Sharjah city.

The results in Figure 10 show the historical per capita water harvesting potential from rooftops in the city averaged over the whole year and over the rainy season. In the calculations, the percentage of rooftops from the built area was estimated to be $80 \%$ and the fraction of rain that was assumed to be collectable was $80 \%$. The data in Figure 10 show that the potential water harvest initially declined between 1976 and 1986 as the built area to population ratio was relatively high in 1976, then the ratio declined dramatically in 1986, then increased gradually thereafter. The data show that the annual water harvest reached about $15 \mathrm{~L} /$ capita per day averaged over 365 days and about $30 \mathrm{~L} /$ capita per day averaged over 180 days of the rainy season. If only the winter season is considered, the water harvest potential can reach about $45 \mathrm{~L} /$ capita per day for 90 days. These numbers are significant and constitute approximately $10 \%$ to $30 \%$ of the water consumption rate of residents in Sharjah city of approximately $200 \mathrm{~L} /$ capita/day. 

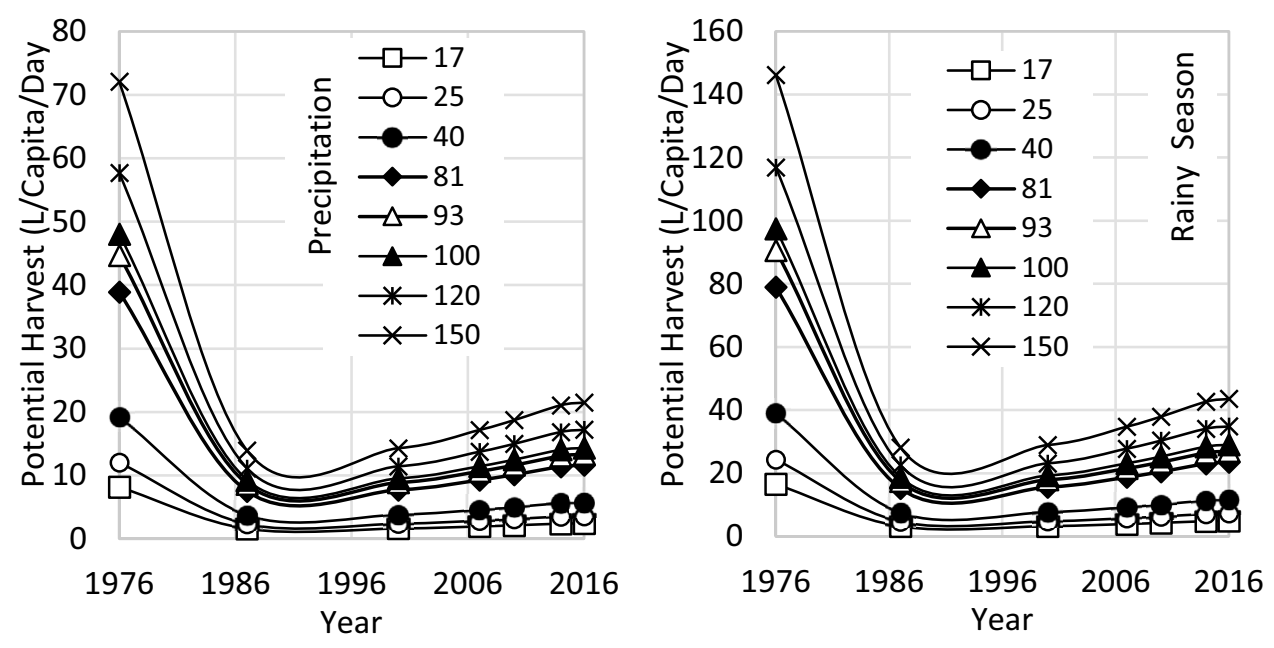

Fig. 10. Potential water harvest from rooftops in Sharjah during a typical year or during the rainy season (180 days) based on $100 \mathrm{~mm}$ average annual rain of which $93 \%$ occurs during the rainy season.

Water harvesting, combined with strategically located local excess rain water storage ponds and promotion of pervious land cover practices are potentially suitable management practices for Sharjah. Such practices support the sustainability goals of the city and may prove feasible in the long-term.

\section{Summary and conclusions}

During the period 1976 to 2016, the built area in Sharjah expanded by four folds while the population increased by about 10 folds. The expansion of built areas significantly increased the following parameters: fraction of impervious land; runoff coefficient; and excess rain, or potential runoff. On the other hand, expansion of built areas significantly decreased the following parameters: fraction of impervious land; maximum potential storage; and minimum rain required to generate runoff.

This study documents the historical expansion of Sharjah city and presents valuable information to help guide urban storm water management and future expansion of the city. Historically, city planners saw no practical value in investing in drainage infrastructure to deal with the occasional and localized road and neighbourhood flooding problems. However, the seriousness of impacts continued to grow as the city turned into a modern metropolitan center. The results from this study suggest that water harvesting can satisfy a significant portion of the water demand in Sharjah city. Water harvesting, combined with strategically located local excess rain water storage ponds and promotion of pervious land cover practices are potentially suitable management practices for Sharjah. Such practices support the sustainability goals of the city and may prove feasible in the long-term.

\section{References}

1. A. Shanableh, and R. Al-Ruzouq, Integration of Multi-Temporal Satellite Imagery in Modelling Urban Expansion Effects on Runoff in the City of Sharjah, United Arab 
Emirates, In: Proceedings of 35th Hydrology \& Water Resources Symposium, Perth, Australia, (2014)

2. E.T. Engman, and R.J. Gurney, Remote Sensing in Hydrology, Chapman and Hall, London, UK, (1991)

3. G.A. Schultz, Remote Sensing Application to Hydrology: Runoff. Hydological Sciences, 41 (4), 453-475, (1996)

4. M. Jain, U. Kothyari, and K. Raju, A GIS-Based Distributed Rainfall-Runoff Model. $J$. Hydrology, 299 (1 \& 2), 107-135, (2004)

5. D. Kumar, and R. Bhattacharjya, Distributed Rainfall Runoff Modelling, Int. J. Earth Sci. Eng., 4 (6), 270-275, (2011)

6. D.S. Lu, Q.H. Weng, Spectral Mixture Analysis of the Urban Landscape in Indianapolis with Landsat ETM Plus Imagery, Photogramm. Eng. Remote Sensing, 70, 1053-1062, (2004)

7. Q.H. Weng, X.F. Hu, and D.S. Lu, Extracting Impervious Surfaces From Medium Spatial Resolution Multispectral and Hyperspectral Imagery: A Comparison. Int. J. Remote Sens. 29, 3209-3232 (2008)

8. C.S. Wu, and A.T. Murray, Estimating Impervious Surface Distribution by Spectral Mixture Analysis. Remote Sens. Environ., 84, 493-505 (2003)

9. A. Singh, Digital Change Detection Techniques Using Remotely Sensed Data. Int. J. Remote Sensing, 10 (6), 989-1003 (1989)

10. Q.H. Weng, Modeling Urban Growth Effects on Surface Runoff with the Integration of Remote Sensing and GIS. Environ. Manage., 28, 737-748 (2001)

11. R. Al-Ruzouq, A. Habib, Linear Features for Automatic Registration and Reliable Change Detection of Multi-Source Imagery, Journal of Spatial Science, 57 (1), 51-64 (2011)

12. USDA, United States Department of Agriculture, Urban Hydrology for Small Watersheds, Soil Conservation Service, Engineering Division. Technical Release 55 (TR-55) (1986)

13. M. M. Sherif, A. Mohamed, A. Shetty, and R. K. Chowdhury, Analysis of Rainfall, PMP and Drought in United Arab Emirates, International Journal of Climatology, DOI:10.1002/joc.3768 (2013) 